throughout the country. The project was the first of its kind, and the lessons learnt from it should allow subsequent surveys to achieve more with less effort. What procedure should be the next for a national audit of this kind? Tonsillectomy? Haemorrhoidectomy? Gastroscopy? Colectomy? There are many which deserve it as much if not more than laparoscopy.

\footnotetext{
${ }^{1}$ Gynaecological Laparoscopy. The Report of the Working Party of the Confidential Enquiry into Gynaecological Laparoscopy, eds G Chamberlain and J C Prown. London, Royal College of Obstetricians and Gynaecologists, 1978.

Phillips, J, et al, Fournal of Reproductive Medicine, 1976, 16, 105

Phillips, J, et al, Fournal of Reproductive Medicine, 1977, 18, 219.

Phillips, J, et al, Fournal of Reproductive Medicine, 1977, 18, 227.
}

\section{A numbers game}

Necessarily, the value of laboratory tests (whether used for discriminating between health and disease, to aid diagnosis, or to monitor treatment) depends on the validity of the reported result. While it is generally accepted by both clinician and laboratory specialist that what is reported can only be an approximation to the truth, and that from time to time errors may occur, the process is given an air of respectability by the tacit acceptance of a normal or reference range of values. These ranges are statistically based and designed to minimise the overlap between values in health and disease. Morgan ${ }^{1}$ has recently reminded us that this naive approach can be misleading, for what we are doing is to compare a measurement at a single moment with a group of values. The central assumption is that the single value is truly representative of the person at that time.

The factors that influence a result are well recognised. Some affect specimen collection-venous stasis, haemolysis, and posture; among analytical factors are the method used and the standard of its performance; while age, sex, and race, and individual factors such as time of day, biological rhythms, diet, exercise, and drugs all contribute to the total variance. The larger the group, the more variables will be incorporated, the larger the reference range becomes, and the poorer will be its discrimination between health and disease. When these variables are reduced by selecting age- and sex-related ranges, attending to details of specimen collection, and using better analytical techniques, the ranges become more refined and apparently more useful. They ignore, however, the important component of intrapersonal variation.

Even if a relatively steady state is reached in an individual, then repeated samples still show a clear intrapersonal variation, ${ }^{2-4}$ and its degree differs for different constituents of biological fluids. ${ }^{45}$ Although intrapersonal and interpersonal variations are inextricably mixed, the greater the contribution of the former to total variance the smaller is the usefulness of the single-sample result. Morgan ${ }^{1}$ illustrates the practical problem from a study in Leeds in which two blood samples for potassium estimation were drawn from a group of patients with an interval of a month. Though the number of patients with hypokalaemia (11 and 15) was similar on the two occasions, only four had a low potassium concentration both times; the patients had a greater intrapersonal variation than did controls.

There is no simple solution. Clearly, every effort must be made to reduce as many of the known variables as possible, ${ }^{6}$ but paradoxically this increases the effect of intrapersonal variation. Replicate testing would give a better measure of an individual's "setting" for a given constituent, but that would raise laboratory and other costs. The ideal would be to test the individual against his own "normal" range-for departure from his own normal is more important than from the conventional group reference ranges. This means serial measurements over a period-one justification for the practice of some laboratories that indulge in cumulative reporting. ${ }^{7}$ Possibly statistical techniques would provide another alternative ${ }^{6}$; but for the present, just as the patient is the best specimen container, equally he seems to be the best guide to biochemical markers of his own health.

\footnotetext{
${ }^{1}$ Morgan, D B, Annals of Clinical Biochemistry, 1978, 15, 49

2 Williams, G Z, et al, Clinical Chemistry, 1970, 16, 1016

${ }^{3}$ Harris, E K, et al, Clinical Chemistry, 1970, 16, 1022.

${ }^{4}$ Pickup, J F, et al, Clinical Chemistry, 1977, 23, 842

' Harris, E K, Clinical Chemistry, 1974, 20, 1535.

${ }^{6}$ McPherson, K, et al, Clinical Chimica Acta, 1978, 84, 373.

${ }^{7}$ Harris, E K, Clinical Chemistry, 1976, 22, 1343.
}

\section{Serotonin, platelets, and autism}

In recent years there has been a spate of research into the role of serotonin (5-hydroxytryptamine, $5 \mathrm{HT}$ ) in neuropsychiatric conditions in childhood. ${ }^{12}$ Serotonin is concerned in synaptic transmission in the central nervous system, and abnormalities in blood serotonin concentrations have been reported in a wide range of neurological and psychiatric disorders. Close parallels exist between the properties of blood platelets and serotonergic synaptosomes in the central nervous system, and the platelet has come to serve as a model of a serotonergic neurone. ${ }^{2}$ But, while there is probably a common mechanism for serotonin binding in the two locations, platelets are more directly exposed to the environment than are brain cells, and the efflux of serotonin from platelets is not necessarily comparable to transmitter release at synapses. ${ }^{3}$ Nevertheless, such parallels have been suggested, and attention has been focused on the possibility of serotonin dysfunction in infantile autism. ${ }^{4}$

Schain and Freedman ${ }^{5}$ were the first to note high blood concentrations of $5 \mathrm{HT}$ in a proportion of children loosely diagnosed as autistic. Similar high concentrations were also found in non-autistic children with severe mental retardation. Since then better controlled investigations have confirmed both observations. ${ }^{6}$ Serotonin concentrations are raised in about a third of autistic children and about half of severely retarded children ${ }^{7}$ other than those with Down's syndrome (in whom the concentrations are abnormally low ${ }^{1}$ ), and in individual children they appear to be stable over several years. ${ }^{7}$ The mechanisms remain obscure. The increase in 5HT does not appear to be due to diet, medication, or other extraneous influences, or to differences in the number of platelets or alterations in monoamine oxidase activity. ${ }^{7-9}$ Cohen et al ${ }^{10}$ have reported lower concentrations of the serotonin metabolite 5-hydroxyindolacetic acid (5HIAA) in the cerebrospinal fluid of autistic than in that of non-autistic psychotic children. The interpretation of that finding is far from clear, however, since neither group differed significantly from controls, whose 5HIAA concentrations were intermediate between the autistic and psychotic groups.

Another approach has been to study the uptake and efflux of serotonin from the platelets of autistic children. ${ }^{6}$ Boullin et $a l^{11}$ reported increased serotonin efflux as a finding specific to autism, but this was not confirmed by Yuwiler et al. ${ }^{12}$ Whether the conflicting results reflect differing biochemical 
assay techniques or disparate diagnostic criteria remains to be determined.

The serotonin firdings may well be important, but their meaning remains obscure. So far attempts to relate serotonin concentrations to clinical differences within autistic or retarded groups have proved rather disappointing. ${ }^{13}$ Moreover, the mental retardation syndromes particularly associated with autism include some with high $5 \mathrm{HT}$ concentrations (such as infantile spasms) and some with low (phenylketonuria). ${ }^{2}$ On the other hand, in Down's syndrome, which is the variety of mental retardation least likely to coexist with autism, the serotonin concentrations are consistently low. Behaviouralbiochemical links warrant further exploration even if, on present evidence, autism seems unlikely to be due to a defined inborn error in a general metabolic pathway, ${ }^{3}$ like that in phenylketonuria.

${ }^{1}$ Coleman, M, ed, Serotonin in Down's Syndrome. Amsterdam, NorthHolland, 1973.

2 Stahl, S M, Archives of General Psychiatry, 1977, 34, 509.

${ }^{3}$ Rodnight, R, in Autism: A Reappraisal of Concepts and Treatment, eds M Rutter and E Schopler. New York, Plenum Press, 1978.

${ }^{4}$ Coleman, M, ed, The Autistic Syndromes. Amsterdam, North-Holland, 1976.

${ }^{5}$ Schain, R J, and Freedman, D X, Fournal of Pediatrics, 1961, 58, 315.

${ }^{6}$ Ritvo, E, et al, in Autism: A Reappraisal of Concepts and Treatment, eds M Rutter and E Schopler. New York, Plenum Press, 1978.

${ }^{7}$ Hanley, H G, Stahl, S M, and Freedman, D X, Archives of General Psychiatry, 1977, 34, 521.

${ }^{8}$ Cohen, D J, Young, J G, and Roth, J A, Archives of General Psychiatry, 1977, 34, 534.

${ }^{9}$ Lake, C R, Ziegler, M G, and Murphy, D L, Archives of General Psychiatry, 1977, 34, 553.

10 Cohen, D J, et al, Archives of General Psychiatry, 1977, 34, 545.

11 Boullin, D, et al, Fournal of Autism and Childhood Schizophrenia, 1971, 1, 63.

12 Yuwiler, A, et al, fournal of Autism and Childhood Schizophrenia, 1975, 5, 83.

13 Partington, M W, Tu, J B, and Wong, C Y, Developmental Medicine and Child Neurology, 1973, 15, 616.

\section{Royal Commission on the NHS}

Faced with the Everest of evidence that they have collected the members of the Royal Commission on the National Health Service must feel rather like a general practitioner confronted with a patient complaining of backache and general debility. The symptoms are painful but ill-defined, the cause is difficult to diagnose with precision, and specialists disagree among themselves as to what ought to be done. Certainly if the Royal Commission members expected their task to be eased by the research they have sponsored, then-to judge by the first report to be published ${ }^{1}$ - they are likely to be disappointed. This study provides eloquent confirmation of most of the criticisms that have been made of the reorganised NHS but provides few new insights and little help in seeking solutions.

The study was designed to test the thesis put forward in evidence to the Royal Commission that the present organisation of the NHS leads to "delays in getting decisions made and consequently to frustration and inefficiency." A team led by Professor Maurice Kogan of Brunel University (an institution which, ironically, was also concerned in setting up the new organisation in 1974) interviewed over 500 people working in the NHS and carried out a number of case-studies of decisionmaking. The survey represents the most comprehensive effort so far made to collect the views of NHS staff; but unfor- tunately it was not rigorous enough in its methods. The inquiry was not based on a representative sample of either people or authorities, and as a result the researchers are mostly unable to quantify their findings, and the report is therefore impressionistic and qualitative rather than conclusive. Given the time constraints under which the team was working-they ${ }_{C}$ had only just over a year in which to carry out their study-no more could perhaps be expected: even so, it is disappointing $\stackrel{\overline{\mathcal{S}}}{\rightarrow}$ that so much research effort should do little more than confirm? what is already known and what could, in any case, have been $\frac{\bar{\sigma}}{\bar{N}}$ obtained from a review of earlier publications.

Almost all those interviewed, it is no surprise to learn, were $\varrho$ in favour of streamlining the present structure--though this consensus disappeared when it came to discussing which tier $\vec{\circ}$ should be abolished. Most were disenchanted with the prin- $\overrightarrow{\vec{H}}$ ciple of coterminosity, and many believed that relations with ${ }_{\sigma}$ local authorities had not improved as a result of reorganisation. $\frac{5}{3}$ Many criticisms were directed, too, against functional management, which was seen as diffusing authority for decision- $\sigma$ making and removing responsibility from the level of indi- $\vec{\infty}$ vidual hospitals to the upper tiers of the administrative $\vec{\nabla}$ hierarchy. One unit administrator is quoted as saying that "buck-passing has become the national sport of the NHS." فे Moreover, consultation adds to delay and uncertainty. The report cites one case where some 40 bodies were concerned in $N$ three years of debate about the occupation of a new hospital wing and another instance where, again, it took three years for a catering manager to get a new rota accepted.

The NHS's elaborately proliferating system of advisory committees attracted hostile comments, too. Doctors in particular complained about the overlapping functions of committees at different administrative levels and of the consequent demands on their time. Nor is this surprising. The survey carried out on behalf of the Review Body, and presented in its latest report, ${ }^{2}$ shows that whereas consultants spent an $\stackrel{2}{\vec{\rho}}$ average of only 4.6 hours a week on administrative and com- $\frac{0}{3}$ mittee work in 1974 the equivalent figure in 1977 was 8.3 hours.

Professor Kogan and his colleagues also draw attention to another problem raised by the advisory committee system. To what extent are the medical members of such committees representatives of the profession-and so performing the essentially political role of acting as spokesmen-as distinct $\delta$ from experts providing technical advice to the health authori-

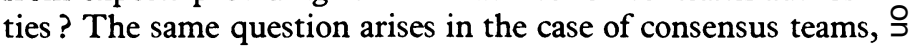
where, as the research report points out, the medical members $N$ may be torn between their representative and expert roles.

Indeed the report is at its best in showing how many of the problems of the NHS arise from the attempt to square a $N$ variety of circles: to create an administrative framework which $\underset{\omega}{\mathbb{N}}$ seeks to reconcile the irreconcilable. Again, this is not an original point. But it is worth stressing that if objectives conflict-if, for example, the aim of policy is both to get speedy $\stackrel{\mathbb{D}}{\stackrel{D}{ }}$ decisions and to make sure that such decisions are acceptable $\stackrel{+}{+}$ because everyone has been consulted-then no administrative structure devisable can avoid strain or tension. Not surprisingly, therefore, many of the report's concluding recommendations $\mathbb{\mathbb { D }}$ are despairingly hortatory: it calls for a "radical change of concepts and values," "further learning of how to relate roles together," and "behavioural" changes. Uplift apart, its main proposal is that each region and each area should review its structure with a view to simplification.

It may indeed be that one of the morals of the 1974 reorganisation is that we should not expect too much from changes in the structure of the NHS: that the difficulties 